\title{
EDUCAÇÃO, DEMOCRACIA E LAICISMO: ALGUMAS APROXIMAÇÕES ENTRE CONDORCET E HOLBACH
}

\author{
EDUCATION, DEMOCRACY AND LAICISM: SOME APPROACHES BETWEEN CONDORCET AND \\ HOLBACH
}

\author{
Marcelo de Sant'Anna Alves Primo*
}

\section{RESUMO:}

$\mathrm{Na}$ "Primeira memória: natureza e objeto da instrução pública" das Cinco memórias sobre a instrução pública, Condorcet considera a educação em sua totalidade, afirma que ela está para muito além de uma instrução positiva, pois abrange todas as opiniões sejam de cunho político, moral e religioso. A liberdade de proferir determinadas opiniões acerca desses assuntos seria uma quimera à medida que a sociedade fosse o parâmetro do que as gerações seguintes devessem acreditar. Aqueles que ingressam em um meio social trazem consigo as opiniões que lhes foram fornecidas pela educação e não são mais livres, transformando-se em meros reprodutores de seus mestres. Em seu escrito A moral universal, o barão de Holbach alinharse-á às teses de Condorcet sobre qual lugar deve ter o ensino religioso na educação pública. Defendendo que sob a tutela de autoridades políticas tirânicas, a educação só poderá ensinar aos guardiões das leis que estas sejam entregues aos caprichos da tirania, aos favores e às violências do poder, denuncia o oportunismo dos ministros da religião em ensinar a moral e imprimir seus preceitos aos mais jovens. No que concerne à Filosofia e ao seu ensino, o diagnóstico do Barão não é nada consolador: em contextos educacionais antidemocráticos e de desnaturalização pedagógica do homem, deliberadamente a Filosofia é proscrita, excluída da educação pública, ficando isolada, enlanguescendo-se à medida que é desprezada.

PALAVRAS-CHAVE: Condorcet. Holbach. Educação. Democracia. Laicismo.

\section{ABSTRACT:}

In the "Primeira memória: natureza e objeto da instrução pública" of the Cinco memórias sobre a instrução pública, Condorcet considers education in its entirety, states that it is far beyond a positive statement because it encompasses all opinions are of a political, moral and religious. The freedom to utter certain opinions about such matters would be a chimera as society became the standard of what the following generations should believe. Those who enter into a social environment bring with them the opinions that have been provided by education and are no longer free, becoming mere reproducers of their masters. In his writing $A$ moral universal, the Baron of Holbach will align himself with Condorcet's theses on the place of religious education in public education. Defending that under the tutelage of tyrannical political authorities, education can only teach law-keepers that they are given over to the whims of tyranny, favors and violence of power, denounces the opportunism of the ministers of religion to teach morals and their precepts to the young. As far as Philosophy and its teaching are concerned, the Baron's diagnosis is not consoling: in anti-democratic educational contexts and in the pedagogical denaturalization of man, Philosophy is deliberately proscribed, excluded from public education, becoming isolated, languishing in measure which is despised.

KEWWORDS: Condorcet. Holbach. Education. Democracy. Laicism.

\footnotetext{
* Bolsista PNPD UFS/CAPES, docente externo do departamento de Filosofia e do programa de Pós-Graduação em Filosofia da Universidade Federal de Sergipe. E-mail: marceloprimo_sp@ hotmail.com.
} 
Le vrai problème reste donc celui-ci: organiser la liberté à l'intérieur même de l'enseignement national. La liberté ne doit pas être une annexe à la nation, un refuge où s'abriteraient ceux que tyrannise l'Etat: la liberté doit imprégner l'Etat laïque enseignant. [Jean Jaurès, Histoire Socialiste (1789-1900), La Législative (1791-1792)].

Tendo como mote principal a ideia de que a instrução pública é um dever da sociedade para com os cidadãos como meio de tornar real a igualdade de direitos, em suas Cinco memórias sobre a instrução pública, Condorcet o define como uma tarefa que consiste em não deixar subsistir nenhuma desigualdade que leve à dependência. A desigualdade de instrução é a pior forma de tirania, não mais sendo "possível aqui a existência de doutrinas ocultas ou sagradas que estabelecem uma distância imensa entre duas partes de um mesmo povo" (CONDORCET, 2008, p. 19). Se é pela descoberta de verdades novas que o homem continuará a se aperfeiçoar obtendo progressos sucessivos em direção ao melhor, seria fundamental implantar uma forma de instrução pública que não deixasse fora de seu raio de ação nenhum talento passar despercebido e que "oferecesse, nesse sentido, todos os auxílios reservados até hoje apenas aos filhos dos ricos" (p. 26) ${ }^{1}$. Mais do que isso, Condorcet sustenta que o tipo de aperfeiçoamento a ser esperado de uma instrução mais igualmente distribuída está longe de se restringir a valorizar os indivíduos nascidos com faculdades naturais iguais, pois além de incentivadora pode ser propagada. Assim, não é tão quimérico crer que "a cultura pode melhorar as gerações e que o aperfeiçoamento das faculdades dos indivíduos é transmissível a seus descendentes. A própria experiência parece provar isso" (p. 28). Sendo a avaliação e incentivo aos talentos tanto como a transmissão da cultura o fim constante de toda e qualquer educação, menos dificuldades surgiriam em relação ao cultivo do espírito pelo estudo, abrindo o caminho para uma maior e melhor assimilação da instrução e mais condições a todos de desfrutá-la. Mesmo aconselhando cautela quando sentencia "não nos vangloriemos de nossas luzes" (p. 29) o autor afirma que não seria possível sem a instrução observar a condição das sociedades sem que também se constate o quanto, nas opiniões e hábitos, resquícios de preconceitos de outrora ainda permanecem em projetos educacionais

\footnotetext{
1 Para Condorcet (2008, p. 26), “Isso já havia sido pressentido mesmo nos séculos de ignorância. Daí vinham todas as fundações para a educação dos pobres. Mas tais instituições, manchadas pelos preconceitos dos tempos em que nasceram, não apresentavam nenhuma precaução para que fosse oferecida aos indivíduos uma instrução capaz de tornar-se um benefício público. Essas instituições eram uma espécie de loteria, que oferecia a alguns indivíduos privilegiados um benefício incerto de elevar-se a uma classe superior; faziam pouco pela felicidade daqueles que favoreciam e nada para a utilidade comum."
} 
que não repensam determinados lugares-comuns pedagógicos. Assim, defendendo que mudar não é capricho de erudição e sim uma necessidade, Condorcet (2008, p. 31) constata que

\footnotetext{
uma nação que se governasse sempre pelas mesmas máximas e cujas instituições não se dispusessem a ceder, diante de mudanças, efeitos necessários de revoluções trazidas pelo tempo, veria sua ruína nascer das mesmas opiniões, dos mesmos meios que haviam antes assegurado sua prosperidade.
}

Argumentando em diversos níveis na "Primeira memória" sobre os diversos aspectos do que deve constituir uma instrução pública ${ }^{2}$, Condorcet chega a um ponto delicado: como uma educação se tornaria independente das opiniões? Considerando a educação em sua totalidade, ela não se limita a uma mera instrução positiva, relativa ao ensino das verdades de cálculo e de fato, "mas abarca todas as opiniões políticas, morais e religiosas. Ora, a liberdade dessas opiniões não seria senão ilusória se a sociedade se apropriasse das gerações nascentes para lhes ditar aquilo em que devem acreditar" (p. 45). Em tempos como os atuais de "escolas sem partido" e outras escabrosidades pedagógicas que pretendem esvaziar o conteúdo reflexivo do ensino e, paradoxalmente, já aí embutido o seu parti pris, Condorcet, há três séculos, parece ir na direção contrária quando estabelece uma relação direta entre educação pública e liberdade de opinião. Ele desmembra a questão em três momentos: 1) o indivíduo que adentra na sociedade, traz consigo opiniões inculcadas pela educação e, sendo perpetuamente servo de seus preceptores, já não pode mais se considerar livre. Devido à sua insensibilidade em relação à sua própria condição, ilude-se crendo que obedece à sua própria razão quando, na verdade, a alienou para outrem; 2) poderiam afirmar que, da mesma maneira, ele não seria livre se recebesse aquelas mesmas opiniões da família, mas nesse caso tais pontos de vista não seriam os mesmos para todos os cidadãos, fazendo-o ver que a sua crença não é universal e levando-o a suspeitar dela. Contudo, Condorcet denuncia o perigo de uma má fé, pois várias vezes ocorre que alguém, percebendo que a sua opinião jamais poderá ter um estatuto universal, ainda persiste nela como se fosse consensual, o que caracterizaria um evidente erro voluntário e uma vaidade pueril; 3) a experiência mostra que determinadas opiniões se fragilizam quando são rejeitadas por contestações contundentes, fazendo a

\footnotetext{
2 Dentre outros, por exemplo: 1) divisão da instrução pública; 2) necessidade de distinguir, em cada uma delas, a instrução própria dos adultos; 3) necessidade de dividir a instrução em vários níveis, conforme a capacidade natural e o tempo dedicado à instrução; os motivos para o estabelecimento de diversos graus de instrução comum; 5) necessidade de examinar cada divisão e cada grau de instrução separadamente. Para mais detalhes ver, em particular, as páginas 32 a 41 da presente tradução.
} 
vaidade em mudar de ideia superar a de não mudar e, mesmo que tais opiniões começassem a ser as mesmas em todas as famílias, se um erro público não lhes proporcionar um denominador comum, logo ver-se-ia elas se cindirem, e aí o perigo viraria fumaça juntamente com a uniformidade.

Toda essa argumentação mostra que Condorcet não era um otimista cego em relação à razão pública e à sua influência nas opiniões, pois os preconceitos disseminados pelo poder público são os piores:

Com efeito, os preconceitos que recebemos da educação doméstica são um efeito da ordem natural das sociedades, e uma sábia instrução, difundindo as luzes, é o seu remédio, ao passo que os preconceitos infundidos pelo poder público são uma verdadeira tirania, um atentado contra uma das partes mais preciosas da liberdade natural. (CONDORCET, 2008, p. 45).

Aqui se desenha a crítica que Condorcet desfere a certo proselitismo político ou “catecismo republicano" (SOUZA, 2008, p. 11) defendido na França na era do Terror e que, ironicamente, o seu maior pregador, Robespierre, acabou sendo vítima de uma religião política vendida como revolucionária ${ }^{3}$. O autor volta à questão da independência, pois um sistema de educação pública deve ser totalmente independente dos poderes religiosos e dos poderes públicos, o que evidencia toda a amplitude da sua concepção de laicismo. Aos poderes públicos cabe garantir uma legislação necessária para a instrução de todos e, por outro lado, não podem se intrometer no que concerne aos conteúdos ensinados. Os professores serão remunerados pelo Estado, mas afastando-se dele em relação à "ideologia" por ele imposta de cima para baixo, jamais confundindo educação com propaganda política e não se submetendo intelectualmente. Nesse sentido, para Condorcet, o processo de produção e disseminação dos saberes, em todos os níveis de ensino tem de ser autônomo em relação a qualquer intervenção exterior de cunho político, ideológico e/ou religioso ${ }^{4}$.

Eis aonde queríamos chegar, em consonância com a proposta do presente trabalho: Condorcet (2008, p. 46) afirma sem hesitar que uma educação completa estender-se-ia às

\footnotetext{
3 Segundo Maria das Graças Souza (2008, p. 11), Condorcet "combate a concepção segundo a qual a educação é um processo de conversão do coração às expensas da razão. Ele recusa a ideia, presente em outros projetos de decreto à mesma época, de que cabe ao Estado ensinar nas escolas uma espécie de 'catecismo republicano', cujos efeitos não seriam em alguns aspectos muito diferentes dos de um catecismo religioso, ou seja, o de obscurecer a razão, mesmo que se trate de um 'obscurantismo virtuoso'."

4 Schopenhauer não estava longe aqui quando denunciou com todas as letras, em A filosofia universitária o direcionamento que o ensino de filosofia estava tomando nas universidades, transformando-se num saber passivo e estéril.
} 
opiniões religiosas, pois é sabido que "a maioria dos homens segue, nesse sentido, as opiniões que recebeu desde sua infância e que raramente lhe vem à mente a ideia de examiná-las”. Se opiniões religiosas se adentrarem na esfera pública, não mais serão uma escolha livre dos cidadãos, mas algo imposto por um poder destituído de legitimidade, pois seria impossível repudiar ou consentir uma instrução religiosa não levando em consideração a educação familiar e sem desrespeitar os pais, se eles entendessem que a sua religião particular fosse imprescindível à moral e a felicidade em algum lugar extramundano. Nesse caso, cabe ao poder público unicamente regular a instrução, deixando às famílias o restante no que concerne a crenças. Sustentando que o poder público não tem o direito de associar o ensino da moral ao ensino de religião, a ação estatal não deve ser nem parcial nem universal, já que as instruções religiosas não podem fazer parte da instrução, devido ao caráter de foro íntimo e caracterizado por uma escolha de consciência independente das religiões. Dessa maneira, "nenhuma autoridade tem o direito de preferir uma à outra, e disto resulta a necessidade de que o ensino da moral seja rigorosamente independente de tais opiniões" (CONDORCET, 2008, p. 47). Mais do que isso, o poder público não pode em assunto algum ter o direito de mandar ensinar opiniões como se fossem verdades inquestionáveis, não deve impor crença alguma e, se alguma opinião lhe parecer perigosa, não será impondo opiniões opostas que ele as combaterá ou prevenirá, mas “afastando-as da opinião pública, não pelas leis, mas pela escolha de professores e métodos; é principalmente assegurando aos bons espíritos os meios de se livrar desses erros e conhecer os seus perigos” (p. 47-48). Enfim, o poder público deve evitar a instrução às corporações de professores que recrutam a si mesmos, pois seu curriculum é o dos esforços para perpetuar opiniões que há muito tempo já estavam na classe dos erros. É o percurso das suas investidas visando à imposição aos espíritos de um jugo com a ajuda do qual esperavam alongar a sua fama ou elevar as suas riquezas, o que acontece em todas as corporações e sejam elas "ordens de monges, congregações de irmãos, universidades, simples confrarias, o perigo é o mesmo" (p. 48). Corporações e instituições dessa estirpe esquecem tanto o dever como o direito do poder público, que é fixar o objetivo da instrução e garantir que seja bem cumprido. Condorcet alude aos defensores do ensino da constituição de cada país fazendo parte da instrução nacional, aí mostrando a necessidade da distinção de falar disso como um fato, ou seja, em unicamente explicar, desenvolver e, quando ensinada, limitar-se a dizer que é a constituição estabelecida pelo Estado e a qual os cidadãos devem obedecer. Contudo, ensiná-la dogmaticamente por meio de um entusiasmo cego 
impossibilitando o seu julgamento aos cidadãos, impondo o que se deve adorar e crer, então "se trata de uma religião política que se quer criar, uma cadeia preparada para os espíritos, e viola-se a liberdade em seus direitos mais sagrados, sob o pretexto de ensinar a amá-la. O fim da instrução não é fazer com que os homens admirem uma legislação pronta, mas torná-los capazes de avaliá-la e corrigi-la" (p. 53). Condorcet aponta para o grave erro em querer submeter cada geração às opiniões e aos desejos das anteriores, quando se perde de vista que é esclarecendo-as progressivamente que cada uma delas consigue se governar mediante a sua própria razão.

Certamente, poderia ser argumentado contra Condorcet quando ele afirma que "sem dúvida, não precisamos temer hoje em dia os mesmos perigos no resto da Europa, onde as luzes não podem concentrar numa casta hereditária nem numa concepção exclusiva" (p. 19) de ser um otimista demasiado em relação à capacidade das luzes racionais em levar o homem a empreender um projeto educacional que extirpe de vez todos os erros que sempre foram obstáculos às pretensões de instaurar e consolidar um verdadeiro e digno ensino público. E, para aumentar a dificuldade, trazer essa confiança do autor para os dias atuais quando são as próprias corporações e instituições de ensino que inventam novas formas de reintroduzir os mesmos preconceitos de outrora que tanto entravaram o progresso científico e o aperfeiçoamento moral. Contudo, o próprio Condorcet já alertava que uma confiança demasiada na razão não faria os indivíduos saírem da condição em que estavam justamente se não estivessem claros os objetivos a que essa razão fosse destinada, no caso aqui, para um amplo e sólido sistema educacional público. A título de nota, no final do século XVIII - 1793 - Condorcet, condenado no regime de Robespierre, quando ainda entendia que o sol só iluminaria os homens livres quando reconhecessem nenhuma autoridade senão a razão, não se esqueceu de propor os meios para fazê-la servir de fundamento e consecução de um projeto pedagógico em todos os níveis e que, para o estabelecimento de uma nova ordem se fazem necessárias medidas deveras eficazes as quais, conforme ao direito e ao dever públicos, determinem o fim último de instruir-se e instruir outrem e cumpri-lo à risca.

$* * *$

Holbach dedica todo um capítulo na terceira parte d'A moral universal à questão da educação, fornecendo um diagnóstico não muito animador quando afirma com todas as letras que "o governo, em todos os países, parece se ocupar muito pouco com a educação dos 
cidadãos. Esse objeto essencial para a felicidade pública é, em geral, totalmente negligenciado" (2014, p. 658; 1778, III, p. 61). Apesar do tom universalista da passagem supracitada, o barão vê claramente que as pessoas do povo, sempre privadas de conhecimento nos governos negligentes ou tirânicos, jamais terão noção alguma do que seja a virtude ou os bons costumes. Corrompido pelo exemplo de seus superiores ou perturbado por suas humilhações, ao homem do povo fica cada vez mais difícil inspirar em seus rebentos sentimentos de honestidade que ele não conseguiu obter por si próprio e que seus pais não lhe transmitiram. Dessa constatação, Holbach chega à questão da religião, pensando em quem poderia afirmar que, em todas as nações, a incumbência de ensinar a moral e inculcar seus princípios na juventude cabe aos ministros da religião. Contudo, “a experiência nos faz ver a impotência de suas lições contra a torrente impetuosa que arrasta incessantemente os homens para o mal" (2014, p. 664; 1778, III, p. 66) ${ }^{5}$. A despeito dos motivos muito nobres, espirituais e muito elevados para a compreensão dos meros mortais para levá-los à salvação, os próprios moralistas religiosos são insatisfeitos com a esterilidade e inaplicação de seus preceitos repetidos incessantemente. Se dogmas funcionam em algumas poucas almas serenas, nada podem sobre a grande maioria devido às grandes forças irresistíveis que parecem impeli-la ao vício. Holbach então afirma que, descartando a imagem de uma maldade inata imputada à natureza humana traçada pela religião revelada, é possível, mediante algumas causas naturais e perceptíveis, explicar a tendência que faz com que os homens enveredem pelo caminho do mal. E quais seriam elas?

[...] a ignorância profunda na qual vemos se atolarem as nações; os exemplos dos ricos imitados pelos pobres; a negligência dos legisladores, que parecem estar comumente muito pouco preocupados em dar bons costumes aos povos ou em fazêlos conhecer os seus interesses, suas verdadeiras relações e os deveres mais essenciais à vida social. Enfim, a mais poderosa dessas causas é a falsa política de tantos príncipes, eles próprios cegos, que muitas vezes parecem querer aniquilar toda ideia de justiça ou de virtude em seus Estados e acreditam que só são grandes se reinarem sobre súditos estúpidos, viciosos e em discórdia por interesses fúteis. (HOLBACH, 2014, p. 664-665; HOLBACH, 1778, III, p. 67).

Apresentadas as causas que impedem que preceitos religiosos tenham um grau mínimo de eficácia no seio de uma sociedade, Holbach não hesita em afirmar que os ministros da religião sempre empregarão esforços inutilmente para moldar os jovens sob os auspícios de

\footnotetext{
5 "Mais l'expérience nous fait voir l'impuissance de leurs leçons contre le torrent impétueux qui entraîne sans
} cesse les hommes au mal". 
uma moral divina amparada em recompensas e punições outra vida. ${ }^{6}$ Da mesma maneira, a filosofia também não logrará êxito em apresentar aos homens uma moral humana fundamentada nas vantagens sensíveis proporcionadas pela virtude nesta vida. Os terrores imprecados pela religião nunca serão de grande valia para tornar os homens melhores, assim como os motivos humanos e os bens que o filósofo promete nesse mundo não passarão de quiproquós enquanto a própria moral tiver como algozes as autoridades políticas, detentoras dos meios mais capazes de assolar os mortais sobre a Terra (2014, p. 665-666; 2014, p. 668). Diante desse quadro funesto, não seria surpreendente o fato de a educação ser rejeitada e até mesmo inoperante em nações corrompidas, quando as máximas da moral são cada vez mais contraditas pelos exemplos, hábitos, instituições, leis e interesses bastante poderosos opostos ao interesse geral. Ora, se tudo concorre contra o estabelecimento de uma boa educação,

todo mundo é instigado ao mal, e ninguém vê interesse em fazer o bem. Daí esses
infinitos embaraços nos quais se lançaram todos aqueles que tentaram apresentar
planos de educação apropriados para formar cidadãos [...] Em poucas palavras, esses
filósofos não perceberam que a reforma da educação dependia necessariamente dos
costumes públicos, que só pode ser obra de um governo esclarecido, vigilante,
equitativo e bem-intencionado. Só o governo pode fazer reinar em um Estado as
virtudes gerais e os costumes públicos. É do tempo e do progresso das luzes que se
pode esperar essa revolução tão desejável nos espíritos dos senhores da Terra. (2014,
p. 666-667; 1778, III, p. 69).

É claro quando Holbach afirma que o único e maior responsável em implementar um projeto educacional rigorosamente reflexivo e prático é o Estado. É essa instância que pode e deve se empenhar ao máximo no sentido de dar uma maior importância à educação e à sua transmissão, transformando-a no motor fundamental da riqueza, prosperidade e firmeza de uma nação, numa França em que instruir-se era privilégio de uma minoria abastada e apoiada principalmente pelas ordens religiosas, enquanto a maioria dos habitantes continuava completamente analfabeta.

Dessa maneira, enquanto os responsáveis diretos pela educação negligenciam o que devem fazer para fomentá-la e fortalecê-la, Holbach arremata: “[...] a educação pública foi, até aqui, pouquíssimo capaz de proporcionar vantagens mais reais à sociedade" e o seu maior

\footnotetext{
6 "En vain les ministres de la religion continueront d'inculquer à la jeunesse les préceptes d'une morale divina appuyée sur les recompenses et les punitions d'une autre vie.” (1778, III, p. 67-68). Segundo Alejandro Rozitchner e Ximena Ianantuoni (2008, p. 122), “a educação religiosa é uma educação na qual a pessoa está sempre sob suspeita, em dívida, devendo provar que assimilou corretamente os princípios morais. Mas, nesse contexto, os princípios morais são mais uma representação do que uma realidade".
} 
defeito "é ser banal, ou não ser adaptada nem ao caráter, nem às disposições naturais nem às tendências das crianças que a recebem [...]" (2014, p. 683; 685; 1778, III, p. 85-86). ${ }^{7}$ Do plebeu ao nobre, do filho do militar ao do magistrado, dos filhos dos poderosos aos dos mais pobres, todos recebem as mesmas lições que alguns alunos destinados a se tornarem teólogos e sacerdotes e “[...] são, com efeito, estes últimos os encarregados [...] de formar os cidadãos; e em toda parte eles não formam senão com os conhecimentos dos quais eles próprios têm necessidade em sua profissão" (HOLBACH, 2014, p. 685; HOLBACH, 1778, III, p. 87). Quando entende que a educação nesse contexto se restringe a uma formação religiosa que não leva em conta a profissão específica daquele que pretende seguir uma determinada carreira, Holbach lembra que em boa parte da Europa, por mais de dois séculos, a tarefa de educar os jovens foi incumbida quase que exclusivamente aos jesuítas, os quais empregaram todas as suas forças para impedirem que as luzes da ciência se adentrassem nas escolas nas quais eles eram os diretores. Estando a educação nacional nessas bases, a rotina é a sua palavra de ordem, apresentando aos homens uma moral monástica e antissocial como se fosse o caminho da perfeição. O barão afirma que não é preciso muita reflexão para perceber que essa moral atroz

\footnotetext{
que só convém a alguns monges, não é de maneira alguma feita para os cidadãos e que, se fosse praticável, acabaria por dissolver a sociedade, por separar os homens e povoar os desertos. É, no entanto, com essa moral que a educação pública nutre comumente os seus alunos, que a admiram como maravilhosa, sem jamais terem a força de colocá-la em prática. (HOLBACH, 2014, p. 686-687; HOLBACH, 1778, III, p. 88).
}

Conforme ao tema proposto aqui, algo mais grave é denunciado por Holbach: a confusão entre uma teologia sofisticada e a própria filosofia na educação pública. A primeira, com ares de racionalidade mas, no fim das contas, obscura, ao invés de instruir a juventude, faz com o que o intelecto se enrede cada vez em falsos problemas. O raciocínio dá lugar a termos ininteligíveis, fazendo com que se perca o gosto pela reflexão e pela busca da verdade e tornando-se uma lógica inócua, servindo de preâmbulo a uma "metafísica íngreme, aérea, na qual a imaginação perpetuamente extraviada, busca sondar penosamente algumas profundezas impenetráveis, completamente estranhas ao bem-estar da sociedade” (HOLBACH, 2014, p.

\footnotetext{
7 "Si l'éducation domestique ou particulière est souvent défectueuse et negligée, l'éducation publique fut jusqu'ici três-peu capable de procurer des avantages plus reéls à la societé [...] c'est d'être banale, ou de n'être adaptée ni aux caracteres, ni aux dispositions naturelles, ni aux penchans des enfans qui la reçoivent[...]"
} 
686; HOLBACH, 1778, III, p. 87-88). Nas entrelinhas, em seu Essai sur les préjugés, Holbach toca num ponto bastante atual pois, afinal, qual o lugar da Filosofia no ensino público? Nas instituições que, teoricamente, teriam como objetivo esclarecer, mas que ainda se identificam e disseminam crendices e superstições particulares que ditam as regras e os conteúdos ensinados, pretendendo-se ser "sem partido" tomando posição escancaradamente, “a filosofia é proscrita, excluída da educação pública, do favor e da presença dos reis, da amizade dos grandes. Ela vive isolada, enlanguesce desprezada, não fala senão a surdos ou a insensatos" (HOLBACH, 2007, p. 185). Mediante sucessivas prescrições, refletir torna-se algo tão olvidado a ponto de ser motivo de chacota quem ousa usar da razão; pensar torna-se sinônimo de rebeldia sem causa, quando alguns têm a coragem de protestar pela e mediante a filosofia em contextos desfavoráveis à sua transmissão e acolhimento; pensar livremente e demência tornam-se sinônimos; falar e escrever livremente agora não passa de uma caprichosa audácia que merece a mais rigorosa das punições. Dessa forma, só restaria ao filósofo "estagnar no esquecimento, a rastejar na indigência, viver na inutilidade ou então, se ousa elevar a sua voz na multidão, não deve esperar senão prisões, ferros, suplícios infamantes" (HOLBACH, 2007, p. 185). ${ }^{8}$

Entretanto, se lá n'A moral universal, o barão afirma que “aqueles que dirigem a educação pública, entre os modernos, se propõem a rodear de trevas e obstáculos todas as ciências para retardar a marcha do espírito humano" (HOLBACH, 2014, p. 688; 1778, III, p. 89), isso se reflete no Essai mais especificamente em relação à filosofia quando ele diz que “de todas as acusações que a ignorância e a má fé intentam contra os filósofos, não há mais grave e mais mal fundada do que aquela que os taxa de uma vontade permanente de destruir sem edificar" (HOLBACH, 2007, XIII, p. 187). ${ }^{9}$ Toda a obra do Barão mostra totalmente o oposto desse clichê sumário do que é ser filósofo e fazer filosofia. Argumentando a favor de uma reforma na educação e uma revolução nos costumes, otimista no progresso da razão a qual pegará pela mão a humanidade e a conduzirá ao mais pleno esclarecimento e confiando na boa intenção dos governantes em instaurarem uma política educacional que englobe tudo o que seja exigido para o seu bom funcionamento, parece complicado nos tempos de hoje como

\footnotetext{
8 “Ainsi, le philosophe doit consentir à croupir dans l'oubli, à ramper dans l'indigence, à vivre dans l'inutilité, ou bien s'il ose élever sa voix dans la foule, Il ne doit espérer que des prisons, des fers, des supplices infamants".

$9 \quad$ "De toutes les accusations que l'ignorance et la mauvaise foi intentent contre les philosophes, il n'en est point de plus grave et de plus mal fondée que celle qui les taxe d'une volonté permanente de détruire sans jamais édifier".
} 
tudo isso poderia ser concretizado. Insistindo cada vez mais no ensino - proselitismo? religioso nas escolas e universidades e colocando como opcional - para dizer o mínimo saberes de cunho reflexivo, como a filosofia, os planos e políticas educacionais atuais não demonstram ter aprendido muito com o Iluminismo, fazendo com que as teses de Holbach - e Condorcet, Rousseau, Diderot e tantos outros que disseram algo a respeito de uma melhor educação - pareçam utópicas e risíveis diante dos caminhos tomados pelo ensino hoje. Obviamente, mesmo tendo seus limites históricos e pedagógicos, a proposta educacional do barão é incisiva no ponto fundamental e o que a torna atual em toda essa discussão até aqui: a principal instância responsável por uma educação pública de qualidade é e sempre será o Estado. À medida que ele é a autoridade máxima, em nome da democracia e do laicismo, o partido mais sensato - dispensado partidarismos religiosos e/ou políticos - a ser tomado seria edificar e fortalecer uma política educacional reflexiva e eficaz, tendo como finalidade última o bem-estar da sociedade e prosperidade da nação.

\section{REFERÊNCIAS}

CONDORCET, Jean-Antoine-Nicolas de Caritas, marquis de. Cinco memórias sobre a instrução pública. Tradução e apresentação de Maria das Graças Souza. São Paulo: Editora UNESP, 2008.

DREUX, Guy. Jaurès et Condorcet: penser la liberté de l'éducation. Regards croisés. Paris: Institut de Recherches de la FSU, septembre 2014, p. 1-5.

HOLBACH, Barão de. A moral universal ou os deveres do homem fundamentados na sua natureza. Tradução de Regina Schöpke e Mauro Baladi. São Paulo: Martins Fontes, 2014.

HOLBACH, Barão de. La morale universelle ou les devoirs de l'homme fondés sur sa nature. Paris: Masson et fils, 1820[1778], III tomes.

HOLBACH, Barão de. Essai sur les préjugés ou de l'influence des opinions sur les moeurs \& sur le bonheur des hommes. Paris: Éditions Coda, 2007.

ROZITCHNER, Alejandro; IANANTUONI, Ximena. Filhos sem deus: ensinando à criança um estilo ateu de viver. São Paulo: Martins Fontes, 2008.

SOUZA, Maria das Graças. Apresentação. In: CONDORCET, Jean-Antoine-Nicolas de Caritas, marquis de. Cinco memórias sobre a instrução pública. Tradução e apresentação de Maria das Graças Souza. São Paulo: Editora UNESP, 2008. p. 7-13. 